\title{
Targeting Academic Engagement in Open Innovation: Tools, Effects and Challenges for University Management
}

\author{
Lars Jonsson $^{1}$ - Enrico Baraldi ${ }^{2}$. \\ Lars-Eric Larsson ${ }^{3}$ - Petter Forsberg ${ }^{2}$. \\ Kristofer Severinsson ${ }^{2}$
}

Received: 5 January 2015 / Accepted: 23 June 2015 /

Published online: 7 July 2015

(C) The Author(s) 2015. This article is published with open access at Springerlink.com

\begin{abstract}
Besides commercialization, university knowledge is commonly transferred through different interactions constituting the so called academic engagement. Very little attention has been paid to professionalizing these various interactions compared to the linear commercialization funnel. In this paper, we conducted a qualitative case study of the innovation support organization at Uppsala University, Sweden, analysing the following: Which mechanisms and tools the university management does apply in order to create targeted open innovation interactions and which effects and challenges emerge when applying these tools? We found that staff with experience of both academia and industry is important for enabling open innovation interactions to evolve and that tools can be used to concretize specific and deeper interactions. However, six challenges was also identified: (1) the intermittent nature of university-industry interactions; (2) lack of codified ways to trace effects; (3) extensive and time consuming preparatory work; (4) the extra resources and low conversion rates in engaging academically unrelated small and medium-sized enterprises (SMEs); (5) high costs of recruiting staff with double competence and running the studied tools; and (6) the interdependencies which makes the system sensitive. Our results indicate that the tools used help the university to follow a mode 3 of knowledge creation. The study addressed the research gap regarding organizational support in academic engagement by indicating which tools can be used by the university management to target and focus industryacademia interactions, their effects and associated challenges. A lot of the effects still need to be codified, and more research is needed to understand their impact over time.
\end{abstract}

Lars Jonsson

lars.jonsson@holding.uu.se

1 UUAB Holding Company, Uppsala University, Uppsala, Sweden

2 Department of Engineering Sciences, Uppsala University, Uppsala, Sweden

3 UU Innovation, Uppsala University, Uppsala, Sweden 
Keywords University-industry interaction - Collaboration - Academic engagement . AIMday · Professional innovation support officers (PISOs) · Mode 3 - Quadruple helix · Targeted open innovation $\cdot$ Technology transfer $\cdot$ Knowledge transfer

\section{Introduction and Aim}

Reflecting a general expectation that publicly funded university research must contribute to economic growth (Balconi et al. 2010), in the last two decades, policy makers have introduced policies and incentives to make universities commercialize academic knowledge via patents and start-ups (Etzkowitz et al. 2000; Bercovitz and Feldmann 2006). However, the university's role in a knowledge economy is more complex than just pushing out inventions to be commercialized. Beside the linear spin-out commercialization track (Clarysse et al. 2005), university knowledge is transferred to the surrounding society in many other even more common ways, namely the interactions constituting the so called academic engagement (Perkmann et al. 2013). The most common transfer channels are publications, conferences and meetings, contract research, informal conversations over organizational boarders, consulting and collaborative research, co-supervising $\mathrm{PhD}$ students and industrial $\mathrm{PhDs}$ (Salter and Martin 2001; Jacobsson and Perez Vico 2010). The contribution of patents and licenses - the cornerstones of the linear spin-out funnel (Clarysse et al. 2005) - has been assessed to cover only between 7 and $14 \%$ of all knowledge being transferred from universities to society (Cohen et al. 1998; Agrawal and Henderson 2002), with a dominant share being transferred instead through the interactive channels of academic engagement.

However, very little attention has been paid to professionalizing the various interactions between academia and external parties which fall outside the linear commercialization funnel. The lack of interest in these interactive and more indirect mechanisms may partly derive from the difficulty in measuring and controlling their results (Baraldi et al. 2014), which may take several years to become visible or remain hidden, embedded in other development processes involving external organizations (Pavitt 2004; Håkansson and Waluszewski 2007). The interactive processes involving universities are complex, including a pluralism of knowledge forms and innovation approaches as pointed out by mode 3 of knowledge production and use (Carayannis and Campbell 2006). Complex and variable interactions between several spheres of society characterize also the quadruple helix and quintuple helix models, stressing the interactions respectively with the civil society and culture and with the physical environment, as a requirement for sustainable development (Carayannis and Campbell 2010; Carayannis and Rakhmatullin 2014).

In this context, universities can theoretically play an important role as sources of ideas that industry can use to develop new product and technology within the "open innovation" paradigm (Chesbrough 2003). However, there are still several barriers to interactions between industry and academia, such as diverging motives, cultures and lack of trust (Plewa et al. 2005; Plewa and Quester 2007). Moreover, while the open innovation approach entails new opportunities, in order for these to be concretely turned into actual innovations, more targeted combinations of various actors' resources need to be created and related in very specific ways to existing network structures (Håkansson and Waluszewski 2007). In other words, open innovation and the triple and 
the Quadruple helix model's interactions do not happen automatically but require considerable efforts by the university management, including particular interactionstimulating tools (Baraldi et al. 2013) allowing a more targeted open innovation approach.

While the literature on commercialization via the linear spin-out funnel (Clarysse et al. 2005) analyses the role, and even measures the performance, of both the individual researchers and of the university management (e.g. technology transfer offices (TTOs)), the literature on academic engagement (Perkmann et al. 2013) only focuses on the motivations, personal characteristics, timing, preferred forms of engagement and barriers for the individual researchers, thereby neglecting the role of university management. In the words of Perkmann et al. (2013): “...for organization-level factors, extant research has focused on technology transfer or licensing offices while the role of organizational support in the guise of industrial liaison offices or business relationship offices has been disregarded. Future research should take these structures into account when analyzing engagement, with the possible outcome that organizationlevel (i.e. university-wide) variables may play a more important role than hitherto thought" (Ibid: 431). Therefore, at a broad level, this paper aims to investigate the role of university management in academic engagement.

Moreover, the existing literature covers established university-industry relations or general principles, advantages and barriers for universities engaging in open innovation interactions with industry and society at large (Cf. mode 2/3 and 3-4-5ple helices models). This literature does not penetrate into how university management concretely promotes academic engagement and achieves more "targeted" open innovation interactions, starting from when university-industry relations do not exist yet. Thus, in order to address this literature gap, the specific aim of this paper is to investigate how university management can "target" open innovation interactions and with professional support stimulate the emergence of specific university-industry relations. For this purpose, we conducted a qualitative case study (Yin 1994) of the innovation support organization at Uppsala University, Sweden, analysing how it favours open innovation by supporting academic-engagement interactions with the surrounding society.

More specifically, the case study addresses these three research questions: (1) Which mechanisms and tools does the university management apply in order to create targeted open innovation interactions? (2) Which effects, in terms of specific university-industry interactions, emerge? (3) Which challenges does the university management face in these processes when applying these tools? In particular, we delimit our focus to three such mechanisms: (a) Uppsala University's recruitment of staff with double competence, capable of building trust and bridging the academia-industry cultural gap; (b) "broader" (i.e. less targeted) mechanisms for capturing potential interaction partners at the early end of the process of relation building (the AIMday tool); and (c) more oriented and targeted mechanisms operating at the level of creation of specific university-industry collaborations (the SMURF tool). Thus, the three mechanisms or interaction-stimulating tools present an increasing degree of focus on specific interaction partners.

Our analysis shows that innovation support officers with both an academic research and an industrial management experience enable building trust between academic researchers and industrial partners, a crucial step in establishing university-industry interactions. The paper also shows that the following steps in developing these 
interactions are addressed by the two analysed tools, whose effects include the creation of contacts, participation, cooperation and collaboration, that is, various types of interactions approaching the ultimate goal of creating long-term deep relationships (cf. Baraldi et al. 2013). However, professional innovation support officers with double competence and tools such as those reviewed in this paper do not remove all challenges in stimulating academic engagement. Difficulties in codifying and following up the long-term results of interactions remain a challenge. The paper is organized as follows: After our theoretical background followed by our methods comes a description of the innovation support organization at Uppsala University and findings about the applied tools. Finally, we discuss our findings in terms of effects and challenges related to using these tools. We also provide suggestions for further research.

\section{Theoretical Background and Framework}

In this section, we present first the background on the changed roles and interaction patterns of universities in relation to industry and society at large, as featured in the mode 1, 2 and 3 models and the triple helix and quadruple/quintuple helix models ("Changing Roles and Interaction Patterns of Universities" section). Then, we connect the paradigm of open innovation with the theoretical approach of Industrial Marketing and Purchasing (IMP), which helps making sense of how generalized interactions concerning innovations are turned into partner-specific deeper relationships ("Targeting Open Innovation: Inspirations from the IMP Approach" section). The reviewed concepts and models are finally brought together into a theoretical framework based on types of interactions, trust between the actors involved, and interactionstimulating tools ("Theoretical Framework" section).

\section{Changing Roles and Interaction Patterns of Universities}

Innovations emerge when new knowledge finds applications and thus become utilized by users (Tidd et al. 2001). Universities can assume different roles in the processes and systems of innovation. Firstly, following a so-called mode 1 (Gibbons et al. 1994; Nowotny et al. 2003; Carayannis and Campbell 2010), they can play a traditional role of contributing discipline-bound discoveries, without considering their application, diffusion and use, because they are companies which take over, develop and finally market these discoveries to end-customers (Narin et al. 1997; Lundvall 1992; Carayannis and Campbell 2010), following a strictly sequential process reflected in the linear commercialization funnel (Clarysse et al. 2005).

During the last 30 years, mode 1 and the linear model have been challenged by nonlinear innovation models that stress the importance of simultaneously coupling the basic research of universities with commercial R\&D applications of firms: In this socalled mode 2, knowledge production is organized around a particular application and relevant need of society (Gibbons et al. 1994; Nowotny et al. 2003). Discovery and knowledge application hence overlap by means of manifold network arrangements connecting highly heterogeneous knowledge producers (Carayannis and Campbell 2010), contributing knowledge from several disciplinary domains and in different forms (e.g. codified and tacit). Mode 2 entails a more socially distributed knowledge, 
which is combined to solve problems in society or the economy. Mode 2 demands more social accountability and a greater sensitivity for the external impact of scientific knowledge: Compared to mode 1, it entails moving from a focus on the values of peer academicians to those of stakeholders outside academia (Ibid).

Lately, a further mode 3 has been proposed, whereby in advanced knowledge societies and economies, a mode 1 and 2 of knowledge and innovation paradigms coexist (Carayannis and Campbell 2006, 2009), at least in certain periods, leading to hybrid thinking, in parallel and simultaneously in different systems (Carayannis and Campbell 2010).

The role played by universities in innovation can be captured also by focussing on how they interact with key external stakeholders. Reflecting the emergence of universities" "third mission" of contributing to societal development, the triple helix model (TH) focuses on the interactions between the state, academia and industry (Etzkowitz and Leydesdorff 2000). In this context, Etzkowitz (2001) coined the term "entrepreneurial university", equipped with "technology transfer offices" staffed with business-oriented officers to foster the commercialization of scientific results through patent applications and out-licensing deals to established companies as well as starting up new companies. The TH model is related to modes 1 and 2, representing their "overlay" in terms of social structures and interactions and has been broadly adopted in national innovation and economic development policies: For instance, Sweden founded in 2001 a new governmental agency, VINNOVA, which exerts strong pressures on Swedish universities to become more entrepreneurial, including funding their innovation supporting units (Eklund 2007).

Carayannis and Campbell (2010) suggest adding a fourth helix to the TH model, represented by innovation's end users belonging to the civil society (media and culture) and new sources of knowledge such as culture and art which add creativity to an innovation system. Thus, the quadruple helix $(\mathrm{QH})$ entails an even more open innovation process than the $\mathrm{TH}$ model, including bottom-up processes (e.g. crowdsourcing and crowdfunding) and the views of a broader portion of society than the business and government spheres dominating the TH model (Carayannis and Rakhmatullin 2014). By adding also a fifth helix, representing environmental effects for achieving a sustainable development, Carayannis and Campbell (2010) suggest also a quintuple helix model. The QH models are connected to mode 3, whereby a university simultaneously can follow or alternate between mode 1 and mode 2 . The $\mathrm{QH}$ model is also considered as a way to overcome the major obstacles in cooperation between academia and business, namely the cultural gap and the need for a high degree of trust (Carayannis and Rakhmatullin 2014; Plewa et al. 2005).

\section{Targeting Open Innovation: Inspirations from the IMP Approach}

The aforementioned models describing the roles and interactions of universities in relation to innovations are matched from the industry's side by the open innovation paradigm, stressing how firms can and should use also external ideas in interactions with users and other sources of knowledge to create new product and services, as opposed to the traditional "closed innovation" relying solely on internal processes (Chesbrough 2003). Universities accordingly assume an important role as sources of external knowledge for companies pursuing open innovation and as a potentially 
relevant partner for industry in innovation. It has to be stressed, however, that open innovation only entails a possibility and potential for universities, rather than a certainty of becoming engaged with companies in concrete innovation activities. In fact, the modes 1, 2, 3 and the $\mathrm{TH}$ and $\mathrm{QH}$ helix models remain at a general and abstract level in discussing the role and interactions of universities, almost assuming that interactions with other spheres and stakeholders are unproblematic. There are instead a number of barriers and challenges to creating these interactions, ranging from diverging cultures between academia and industry (Plewa et al. 2005) to the difficulty in building the trust necessary to create long-term and deep relationships (Plewa and Quester 2007; Håkansson and Snehota, I 1995).

open innovation is also often viewed in very optimistic terms, making the boundaries between a firm and its environment more permeable so that innovations can easily transfer inward and outward. In a more extreme sense, the open innovation paradigm can be interpreted as going beyond just exploiting external "sources of innovation" such as customers, competitors and academic institutions, as a broader change in the use, management and deployment of intellectual property (West and Gallagher 2006). Exploring internal and external sources for innovative opportunities is pivotal, but this exploration needs to be integrated with the firm's capabilities and resources, all the way to the exploitation of these opportunities through multiple channels. There is accordingly no easy recipe on how to make open innovation work, and the original paradigm concerns more the general principles and abstract processes, rather than its detailed functioning, including its barriers and challenges. To start with, open innovation also entails a series of disadvantages, as pointed by Dahlander and Gann (2010), such as risk of leakages to competitors and of outsourcing core activities, difficulty in capturing the benefits of external knowledge, problems in focusing on too many alternatives and difficulty in maintaining ties with several partners. Moreover, innovating with partners also entails sharing risks and rewards. All in all, the concrete manifestations of open innovation between two specific partners, especially when involving also universities, are seldom automatic outcomes but require considerable efforts from both parties.

A theoretical perspective that accounts for this complex and demanding nature of innovation-related interactions is the IMP approach which predates the formulation of the open innovation paradigm and thoroughly penetrates the specific mechanisms behind inter-organizational relations. The IMP approach stresses how the business landscape is imbued by interdependences across organizational boarders (Håkansson et al. 2009), which emerge as organizations interact with specific counterparts during long-term relationships (Håkansson 1982). These interactions do not only shape the interacting companies themselves but also their technologies and their innovation possibilities. According to the IMP approach, even if there may seem to be several potential counterparts for innovation, each company focuses and deepens its interaction only with a restricted set of partners, with whom a full-blown relationship is developed (Håkansson and Snehota, I 1995). Therefore, while open innovation stresses the openness of companies' innovative activities (Chesbrough 2003; vonHippel 2005), the IMP approach suggests that this openness does not mean a total freedom of interacting with any partner or of changing constantly innovation partners: In practice, companies are very selective when it comes to choosing whom they collaborate with for innovation and tend not to change their preferred partners (Håkansson and Waluszewski 2007). 
Further, IMP researchers identify a set of interdependencies that stretch from the two interacting parties (the "dyad") to a whole network of indirectly connected parties (Håkansson and Snehota, I 1995; Håkansson et al. 2009). This business network connecting several companies will create a threshold for any invention, especially if it is of a breakthrough type. Paraphrasing the IMP motto that "no business is an island" (Håkansson and Snehota 1989), we can also state that "no innovation is an island". It is not until an invention has been successfully embedded in the three settings of users, producers, and developers that it can be viewed as a successful innovation (Håkansson and Waluszewski 2007). An invention must provide benefits in all of these three settings to be able to successfully reach the market. And, since businesses are increasingly connected and dependent on each other, this means showing benefits in many aspects before an invention is accepted. Every invention faces the existing network with its investments in product development, marketing but also production and supply infrastructure (Baraldi et al. 2011a, b). The new solution's benefits need to be attractive to a majority of the players in the existing network to become accepted and embedded, whereas much of universities' cutting-edge knowledge and the related breakthrough inventions can be viewed as a threat by some established companies, as they collide with their investments and knowledge bases (Håkansson and Waluszewski 2007). Further, even if there are sector-specific variations, universities are seldom the preferred type of partner for R\&D collaborations, as customers and regular suppliers usually occupy this role (Håkansson 1989).

There are accordingly several reasons to question the ideal of a "perfect match" between academia and industry when it comes to innovation-related collaborations. Further, the IMP approach suggests limits to how "open" and free from existing structures innovation can be: Innovation processes seem to be targeted and involve recurrently specific counterparts, which makes it also difficult for universities proposing themselves as entirely new innovation partners to companies. In this sense, tools such "Easy Access IP" platforms (Fishburn 2014) that offer, sometimes even free-ofcharge, university-based inventions to industry may well be "too open": Without an underlying deep interaction with specific industrial partners, these platforms would provide just an additional marketing channel, but no guarantee of the willingness of industrial counterparts to engage in actual interactions with academia. Moreover, historical data show that the overwhelming majority of university patents remains unused as no licensee shows interest, even if highly professional TTOs push them out (Trune and Goslin 1998; Litan et al. 2007; Powell et al. 2007; AUTM 2012). It is a minority of truly interesting patents that generate the greatest majority of revenues, while most others only cause losses to TTOs, even at the universities most successful in technology transfer.

\section{Theoretical Framework}

All in all, while such models as mode 2 and TH imply that in principle universityindustry collaborations represent an ideal match between fully complementary and compatible partners, in practice university-industry collaborations are not the norm nor automatic and strictly necessary interactions. It becomes therefore even more important to understand which processes and structures intervene when university-industry interactions do happen, especially if they thrive and deepen into full-blown relationships 
(Håkansson and Snehota, I 1995). It is in fact important to recognize that these interactions vary in terms of depth, intensity, adaptations and interdependence - some of the key dimensions of inter-organizational relationships (Ibid).

In this regard, Baraldi et al. (2013) identify a typology of university-industry interactions based on increasing depth, intensity and importance for the parties: from shallow "contacts" (a simple acquaintance), to "participation" in meetings and discussions (with minimal exchange of resources), to actual "cooperation" (entailing knowledge exchange andjoint activities), to deeper "collaborations" (entailing closer combinations of resources towards a common goal) and, finally, to full-blown "relationships", characterized by interaction episodes repeated over the long-term, resource adaptations and high levels of interdependence (Ibid). Needless to say, the shallower types of interactions are the most simple to obtain, whereas the deeper and complex interactions (collaborations and relationships) are the most demanding and hence difficult to achieve. In order to move along this ideal ladder, there are several barriers that need to be overcome, such as divergent motives and time orientation between academia and industry, different cultures, languages and core values (Plewa et al. 2005; Plewa and Quester 2007). Therefore, whenever deeper interactions emerge or are created, we can expect that some elements have intervened to help the parties overcome those barriers. In the following, we will focus on the elements put into play by one of the parties in university-industry interactions, namely the university management - the other two being individual academic researchers and companies (cf. Baraldi et al. 2013).

In fact, the specific content of university-industry interactions involves exchanges and combinations of knowledge and other resources between the two main actorsresearchers and companies, who conduct often jointly such activities as sponsored research (e.g. testing), informal discussions, personnel sharing (including industrial PhDs) and provision of lab facilities (Nilsson et al. 2010; Jacobsson and Perez Vico 2010). However, next to the two parties actually performing those activities, the university management (e.g. Industrial Liaisons Offices, Business Relationship Offices or TTOs) represents a third actor who assumes a key role in connecting researchers and companies (Jones-Evans et al. 1999; Debackere and Veugelers 2005; Tether and Tajar 2008; Yusuf 2008; Wright et al. 2008; Lai 2011; Resende et al. 2013; Ankrah et al. 2013). Even if Perkmann et al. (2013: 247-8) point that "...there is no conclusive evidence on the role of formal organizational support structures...for stimulating academic engagement", the specific offices created often centrally by the university management play the role of intermediaries acting as "technology translators" between industry and academicians, understanding their specific needs and recognizing strongly with both groups (Ankrah et al. 2013: 62).

Next to a straightforward brokerage role of covering the typically missing links between industrial and academic networks, intermediary offices such as Industrial Liaison Offices (ILOs) and TTOs also act as "representatives" of the perceptions, ideas and expectations of one group to the other, helping to overcome the cultural distance 2 and language barriers between them (Wright et al. 2008: 1208). The university management, in its intermediating role, is not simply a switchboard making connections, but intervenes more as "knowledge brokers" who, while moving back and forth between "worlds", produce and facilitate a movement and transformation of knowledge between "producers and users of knowledge" (Meyer 2010:121-3). 
After initial contacts and connections - ideally provided by TTOs and ILOsdeveloping a deeper form of interaction requires that the two parties commit resources and time to each other (Håkansson and Snehota, I 1995). However, as pointed by interorganizational theory, commitment to a relationship is closely related to the emergence of trust between the parties (Morgan and Hunt 1994). Trust indicates an actor's confidence in the counterpart's reliability and integrity and a belief that the latter's conduct will bring positive outcomes to the former and no unexpected negative ones (Anderson and Narus 1990: 45; Morgan and Hunt 1994: 23). In creating a positive spiral of trust and commitment in a university-industry relationship, an important step is inducing the parties to trust each other so to overcome the initial barriers deriving from diverging motives, time orientation and core values (Plewa et al. 2005: 449). Making the motives of the two parties converge requires, in turn, that academic incentives (e.g. research funding and publication) become attuned with industrial needs (e.g. knowledge exploration or new product development): Converging motives open up then for resources mobilization in a deeper relationship. University management's TTOs and ILOs can contribute to build trust between academic researchers and industry, provided that they are themselves trusted by these actors. Being trusted requires, in turn, that these management offices hold a credibility and legitimacy of their own, based on control over relevant skills and resources and recruitment policies, reflecting the professionalization of third-stream support functions occurred since the late 1990s (Wright et al. 2008).

Finally, alongside professionalization of its personnel (Rhodes and Sporn 2002; Clark 2003), the university management can also deploy specific interaction-stimulating tools, such as particular meeting forums, project formats, incentivizing schemes and organizational structures, which aim to create one or several typologies of universityindustry interactions (Baraldi et al. 2013). For instance, Wright et al. (2008: 1219) mention the "Medici Fellowship Scheme" in UK universities, an interactionstimulating tool based on research fellows, often post-docs, who receive IP and business management training and are expected to act as promoters of commercially oriented activities in their research department: This makes them de facto a new class of intermediaries operating outside a given TTO or ILO, but in concert with it. Another tool from the UK are the Knowledge Transfer Partnerships (KTP), a government sponsored scheme bringing together an academic researcher, a recent graduate and an external organization through the establishment of a collaborative project lasting 12-36 months and aiming toenable knowledge transfer between these partners (Gertner et al. 2011). Philbin (2010) describes how the Imperial College, London, built both industrial sector-specific and process-oriented platforms to facilitate collaboration. More abstractly, Peças and Henriques (2006) develop a general model aimed to enhance the collaborative culture between SMEs and universities by making researchers, engineering students and SMEs' managers working together in a particular sequence of steps to solve a mutually defined problem. The interaction-stimulating tools reviewed in the literature are mostly from the UK context or presented in abstract terms. Therefore, the tools presented in this paper contribute to this literature also with tools from Sweden as well as a more detailed description of their functioning.

Summing up, the key concepts reviewed in this section are reunited in the framework on Fig. 1 below, stressing the importance of trust between the three actors involved and of specific tools in order to create interactions between academic 


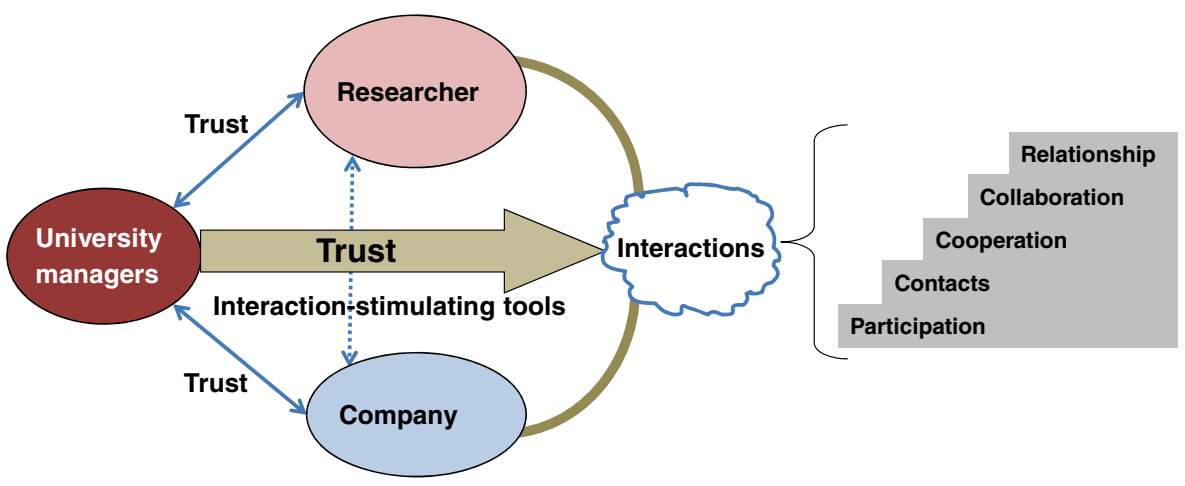

Fig. 1 A theoretical framework over university-industry interactions

researchers and industry. Further, as indicated by the ladder, these interactions can assume different degrees of depth (Baraldi et al. 2013), depending also on the extent of trust among the parties and the particular interaction-stimulating tool deployed. Next to applying this theoretical framework to the case of Uppsala University's innovation support organization, this paper also identifies the challenges that university management faces when applying the reviewed tools to support university-industry interactions. As an important mechanism in the functioning of these tools, we also discuss the matching between academic incentives (e.g. external funding) and industrial partners' needs and whether this matching can be improved by innovation support officers capable of further increasing the trust between researchers and industry partners.

\section{Methods}

The data about Uppsala University (UU) featured in this paper are part of a larger research project started in 2009 which compares the innovation strategies of three Swedish universities, the other two being the Karolinska Institute (KI) and MidSweden University (MSU). These three institutions were selected as comparative cases due to clear differences in their innovation strategies, with MSU focussing on student entrepreneurship in the area of services, KI focussing on an advanced bio-sciences linear spin-out funnel (Clarysse et al. 2005), and UU increasingly embracing informal mechanisms of academic engagement (Perkmann et al. 2013). Therefore, UU was chosen for further analysis as its innovation strategies fit well the focus of this paper on targeting open innovation within the frame of academic engagement.

The empirical material and analysis presented in this paper rely on multiple sources of data so to enable triangulation and enhance the credibility of our findings (Lincoln and Guba 1985). Collected between 2009 and 2014, these multiple sources of data include over 40 direct observations and participations to the tools and activities developed by Uppsala University's innovation supporting unit, over 80 qualitative in-depth interviews with representatives from all the involved organizations (including companies and academic researchers), three surveys administered to populations between 1000 and almost 4300 in size belonging to relevant target groups (researchers and industry representatives) and a large amount of documents (e.g. applications, 
strategic plans, project plans, project meeting minutes, brochures and other information materials).

Two of these surveys were performed by an independent researcher in May 2010 and 2013 and asked, via a web-based questionnaire, all researchers and $\mathrm{PhD}$ students at Uppsala University about their knowledge and personal experience of the activities of the innovation support units. The same questions were asked in 2010 and 2013 so to identify the evolution in the respondents' opinions and attitudes about Uppsala University's innovation support. The response rates were 916 out of 3441 (26.6\%) and 708 out of $4286(16.5 \%)$, respectively, and these respondents were on both occasions assessed as being a representative sample of both the researchers and $\mathrm{PhD}$ students target populations at Uppsala University. A particular question in the survey about the willingness to recommend these innovation support units to colleagues is utilized in this paper as a proxy of the researchers' trust in their officers.

Next to the above data sources, two of the paper's authors have been part from start of the managerial team of Uppsala University's innovation supporting organizations and thus directly involved in building and developing the structure, processes and tools described in this paper. Our method thus also includes participant observations from more than 15 years starting at the end of 1998, within an "action research" design (Levin and Greenwood 2001). As a way to counterbalance the risk of bias and selfreferencing of action research, it is the other authors of this paper who have been conducting the analysis of the empirical materials and especially of the experiential insights provided by the authors belonging to Uppsala University's innovation units.

Among the extensive empirical materials and the entire innovation support structure and processes of Uppsala University, three particular elements have been selected for discussion in this paper as fitting our research purpose of understanding how academic engagement can concretely target open innovation by creating specific universityindustry interactions. Reflecting our theoretical frame (see "Theoretical Framework" section), we accordingly selected (1) the recruitment of "professional innovation support officers" (PISOs) capable of building trust with academic researchers and industry; (2) the AIMday conference, an interaction-supporting tool bringing together for one day discussions academia and industry based on questions formulated by companies; and (3) the SMURF project, another tool aiming to create collaborations between SMEs lacking previous interactions with academic researchers. In relation to other tools reviewed in the literature and to our theoretical frame (see Fig. 1 above), the three selected mechanisms follow therefore a logic of increasingly targeting open innovation interactions: from generalized support to university-industry interactions via trust-building (PISOs) to concrete tools that start broader (AIMday builds contacts and initial cooperation) and then become more targeted (SMURF creates deeper collaborations via specific funding).

Data about the activities of PISOs derives primarily from about 20 interviews (conducted between 2009 and 2013) and the direct experience of the authors who have recruited and currently lead these officers. Data about AIMday derives from 23 indepth interviews, informal discussions with PISOs about AIMday and its development, 13 semi-structured interviews with participating companies and academic researchers, participant observation to six different AIMdays and observation of five planning meetings. Next to this qualitative data, an online survey was addressed in 2013 to all 1118 participants in the first 20 AIMdays in order to probe their attitudes towards 
AIMday and trace its effects (see Table 1 in "AIMday's Effects" section). This survey had a response rate of $29 \%$. Data about SMURF derives from a total of 40 interviews, 20 with partaking SMEs and 20 with academic researchers, 17 participant observations to project meetings in 2012-2014, as well as full access to all project documentation. All these data have been analysed keeping in mind the three specific research questions presented in the "Introduction", namely identifying (a) the key mechanisms behind each of the three components in Uppsala University's academic engagement strategy; (b) the effects produced by each of them, as well as (c) the challenges implied in their implementation.

\section{Interaction-stimulating tools at Uppsala University, Sweden}

Uppsala University, Sweden, is Scandinavia's oldest university, founded in 1477. It is an internationally recognized comprehensive university with 45,000 students and a turn-over of about $€ 700$ million. Almost $70 \%$ of these funds are used for research and doctoral education, which makes it the most research-intensive Swedish comprehensive university. As Sweden applies the professor's privilege, commercialization activities were not explicitly pursued by the university management until 1999, when a holding company, UU Holding, became operational with the purpose of investing early seed money in new ventures and create out licensing deals. Next to the commercialization focus of UU Holding, in 2007 Uppsala University Innovation (UUI) was created to provide professional support to interactions between academicians and existing companies or other external organizations, thereby focussing explicitly on academic engagement. In 2015, UUI employed 18 PISOs, the majority of whom had a combined

Table 1 Opinions of participants to all AIMday events 2008-2013

\begin{tabular}{|c|c|c|c|c|c|c|}
\hline & \multicolumn{3}{|c|}{ Academic delegates } & \multicolumn{3}{|c|}{ Industrial delegates } \\
\hline & Disagree & Neutral & Agree & Disagree & Neutral & Agree \\
\hline $\begin{array}{l}\text { AIMday facilities fruitful interactions between } \\
\text { academic researchers and practitioners }\end{array}$ & $10 \%$ & $13 \%$ & $76 \%$ & $8 \%$ & $6 \%$ & $86 \%$ \\
\hline $\begin{array}{l}\text { Through AIMday, scientific knowledge becomes } \\
\text { useful for practitioners }\end{array}$ & $12 \%$ & $12 \%$ & $76 \%$ & $13 \%$ & $16 \%$ & $71 \%$ \\
\hline $\begin{array}{l}\text { The AIMday activity is very good for creating new } \\
\text { personal relations }\end{array}$ & $10 \%$ & $14 \%$ & $76 \%$ & $5 \%$ & $11 \%$ & $84 \%$ \\
\hline $\begin{array}{l}\text { The knowledge exchanged in the discussions on } \\
\text { AIMday is/has been practically useful in my work }\end{array}$ & $48 \%$ & $28 \%$ & $24 \%$ & $26 \%$ & $23 \%$ & $51 \%$ \\
\hline $\begin{array}{l}\text { Through the discussions on AIMday, specific } \\
\text { problems related to my work has been solved }\end{array}$ & $69 \%$ & $20 \%$ & $11 \%$ & $49 \%$ & $25 \%$ & $26 \%$ \\
\hline $\begin{array}{l}\text { Through AIMday, one gets better insights into what } \\
\text { kind of challenges practitioners are facing }\end{array}$ & $8 \%$ & $26 \%$ & $66 \%$ & $14 \%$ & $19 \%$ & $67 \%$ \\
\hline $\begin{array}{l}\text { In general, AIMday facilitates the creation of useful } \\
\text { academic-practitioner collaboration projects }\end{array}$ & $19 \%$ & $20 \%$ & $61 \%$ & $11 \%$ & $18 \%$ & $73 \%$ \\
\hline $\begin{array}{l}\text { My participation on AIMday has led to the formation } \\
\text { of collaboration } \operatorname{project(s)}\end{array}$ & $68 \%$ & $10 \%$ & $22 \%$ & $45 \%$ & $15 \%$ & $40 \%$ \\
\hline
\end{tabular}


background of academic research and business development experience. We describe first the role of the PISOs in promoting academic engagement and how they contribute to building trust in academia-industry interactions ("PISOs"). Then, we describe two specific tools developed at Uppsala University to stimulate interactions and favour open innovation in surrounding ecosystem: the AIMday concept ("AIMday") and the SMURF platform (“SMURF”).

\section{PISOs}

Uppsala University's early attempts to create a structured innovation support entailed the recruitment of experienced business developers. However, as these individuals lacked academic experience, they faced tremendous difficulties in being accepted as "colleagues" by the academic researchers, who viewed them mostly as "money makers", incapable of understanding or adding academic value. Therefore, Uppsala University opted to man its innovation supporting units with PISOs possessing double competence, combining an academic research track with experience from managerial positions in business or health care. The idea was that this should give the staff an ability to understand the driving forces within academia as well as those in the external organizations with which collaborations were to be built, thus making PISOs capable of acting as brokers and negotiators building bridges that could reach over existing cultural clefts (see Fig. 2).

These PISOs are like spiders in a net, acting proactively to join the competencies and efforts from different parties according to identified challenges in society and different possibilities such as calls for applications. When the contacts between researchers and

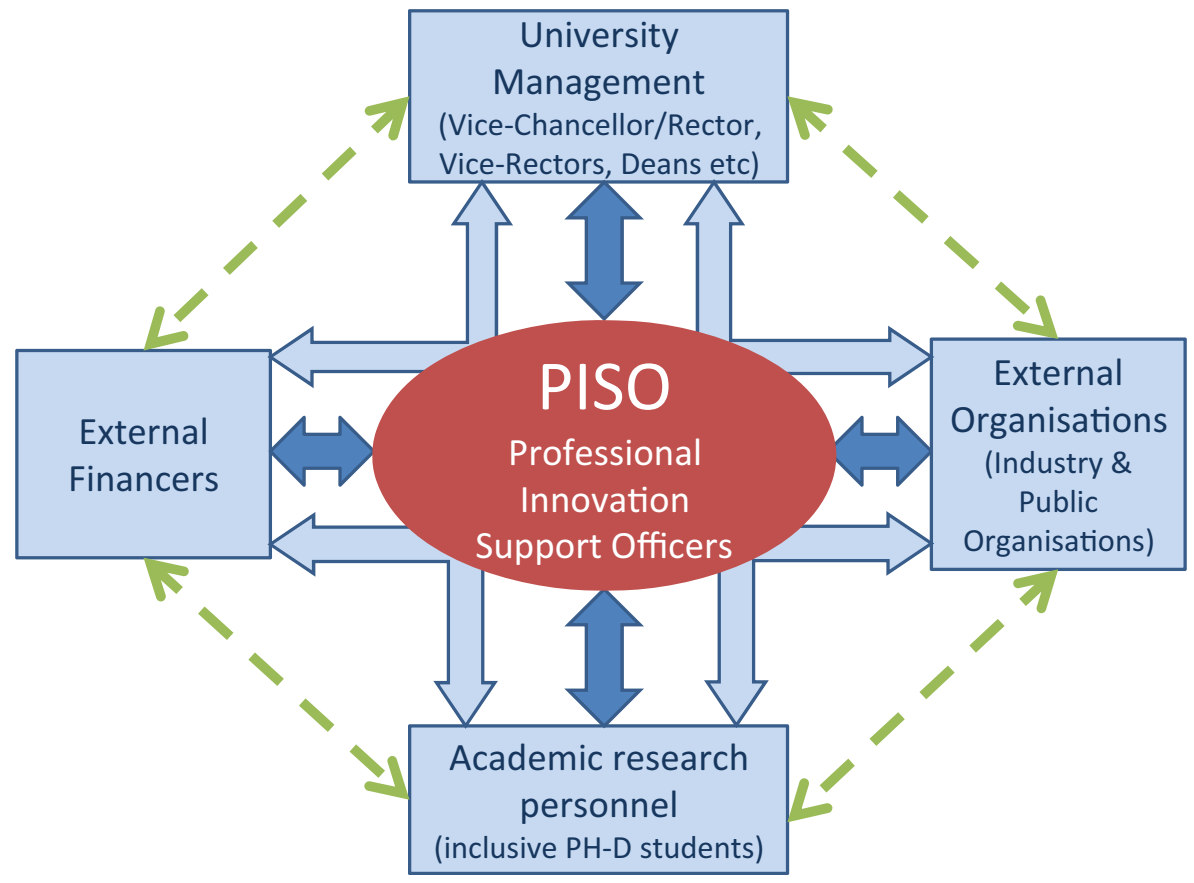

Fig. 2 PISOs act like spiders in a net identifying, forming and coordinating collaborative projects 
external organizations are established, they support the formation of specific projects by organizing necessary meetings and act as mediators and coordinators in forming a collaborative platform. When projects take off, they are managed directly by the parties involved (dotted lines) and the PISOs only intervene when necessary, most often as mediators when difficulties and misunderstanding arises.

Next to organizing meetings to start and facilitate university-industry interactions, PISOs also have the ability to understand the needs and challenges for the involved parties and can exploit both internal and external networks to invite persons who add value on the discussion topic. Their experience and position also makes them trustworthy enough so that all invitees, both from industry and faculties, come to the meeting knowing that the time will be well managed. UUI operates more broadly than direct commercialization through start-ups and out-licensing deals and also supports the forming, application and managing of large collaborative projects with external funding. This broader focus, which is also more sympathetic to the needs of academia, together with the double experience of the PISOs, gained the trust of academic researchers (see "Trust and Number of Participants in UUI's Activities" section below for details).

\section{AIMday}

AIMday stands for "Academy Industry Meeting day" and is a process where researchers and industry meet to discuss questions formulated by participating companies (see Baraldi et al. 2011a, b; Baraldi et al. 2013). The purpose of AIMday is to arrange a meeting that enables common interests between scientists and companies to be identified through open discussions. AIMday is explicitly focused on a series of smaller parallel workshops where specific questions posed by companies are discussed by researchers which have been carefully selected by the organizers (see Fig. 3 below).

All companies that submit at least one question are welcome to participate. The same goes for researchers and $\mathrm{PhD}$ students who show an interest in discussing the submitted questions. All questions formulated by companies are disclosed on the web page especially designed for the day. Then, each question is assigned a workshop where a multidisciplinary group of researchers participates to provide as many perspectives to the issue as possible. The discussions have a time limit of $1 \mathrm{~h}$ per question to make it more focused and efficient. Between each workshop, there is a pause of at least $30 \mathrm{~min}$ to allow informal discussions and networking.

Arranging an AIMday requires a lot of preparation. First, it is crucial to find a good theme for the day, capable to attract both enough qualified researchers willing to participate and companies with interesting questions. To be able to fulfil these criteria, it is essential that the organizers have access to already established networks in the area both inside and outside the University. Secondly, the PISOs need to explain and prepare

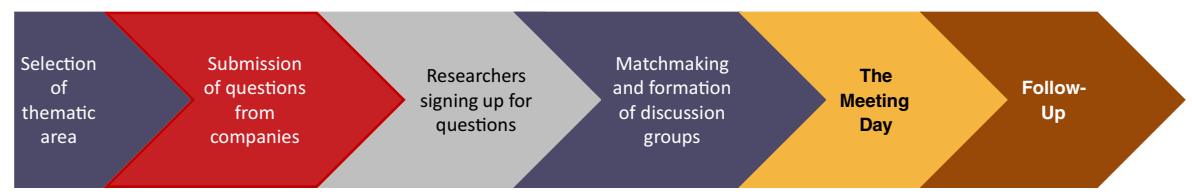

Fig. 3 The AIMday process 
the companies through intensive communication and make sure that they really submit questions. Thirdly, the PISOs often need to ask the companies to reformulate their questions or make an interpretation themselves and suggest a transformation of the question into more research-based nomenclature and then ask the companies if this new formulation conforms to their will. This means that it is a big advantage if the PISOs are familiar both with the business and the research in the field.

Fourthly, the PISOs need to remind the researchers to sign up for the submitted questions and make sure that several researchers are assigned to the question, which will give different perspectives in the discussion and provide the companies with possible different angels of attack. Sometimes, the PISOs have to find a complementary researcher when they think a perspective is lacking. Fifthly, the organizers have to arrange a schedule for the day which allows the researchers and the companies' representatives to participate in so many workshops as possible and yet get plenty of time also for informal meetings. Sixthly, the PISOs have to make sure that the researchers really turn-up for their workshops and be able to make ad hoc solutions if someone cannot attend with a short notice.

For most of these steps, special web-based software has been developed at Uppsala University which saves time and gives the organizers a reliable overlook of the situation day by day during the preparatory phase. All in all, these considerable efforts in getting and fitting the questions to the researchers as well as constructing good discussion groups are pivotal for AIMday. Even if the PISOs have to invest a lot of time in the preparation phase, much of this job is in line with and favourable for their duties as a PISO, so it has shown to be well-invested resources.

AIMday started as a concept first tested as a 1-day materials science conference in 2008 and during the following years was expanded by UUI's PISOs to other scientific domains of Uppsala University inclusive medicine, pharmacy and also social sciences. Starting from 2011, AIMday also spread to other Swedish universities, such as the Royal Institute of Technology, Stockholm, and Lund University, and from 2014 also to foreign universities, namely Edinburgh University and Nelson Mandela Metropolitan University in South Africa. Figure 4 shows details of the 22 AIMdays performed until December 2013 in several academic disciplines (Materials Science, Life Sciences, Humanities/Social Sciences) with the participation of seven universities.

\section{SMURF}

SMURF stands in Swedish for "small and medium-sized companies collaborating with Uppsala's universities". It is a structured platform to stimulate SMEs with no or limited previous academic experiences to use the knowledge and expertise at the university for developing new methods and products. This approach was tested through a 3-year (2011-2013) project with funding from the regional EU funds and conducted jointly by Uppsala University and the National University of Agricultural Sciences (SLU), also located in Uppsala (see also Baraldi et al. 2013). As small companies, which are not spin-offs from universities, have problems to establish relations with Academia, this project provided about 30 SMEs with financial support to establish academic collaborations assuming they could in this way benefit from academic research and thus support their economic growth. 


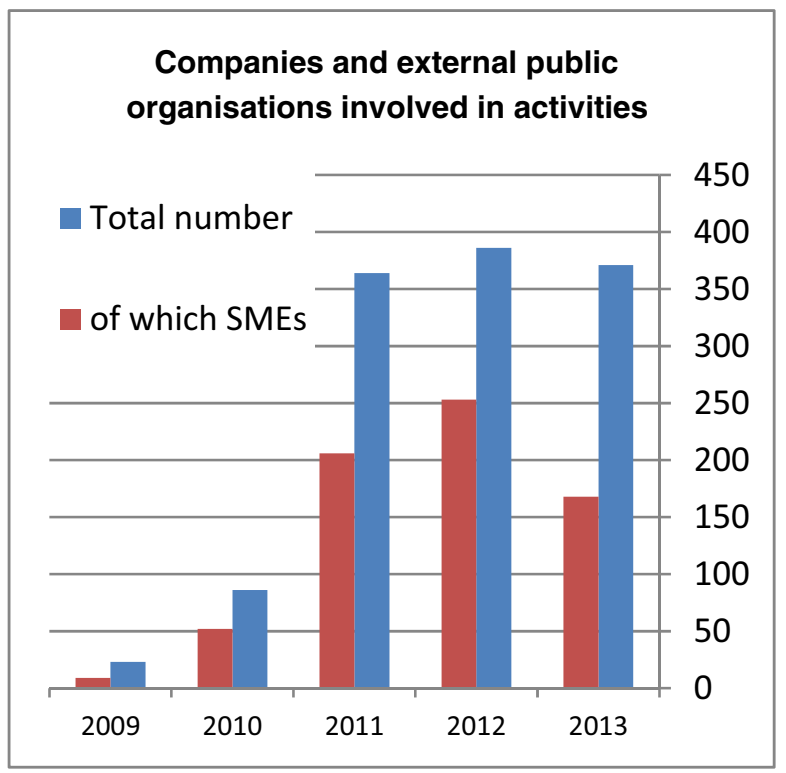

Fig. 4 Number of AIMday performed annually

Small companies who did not have previous contacts with the two universities were identified and contacted by the universities' PISOs. Due to difficulties in finding interested SMEs which lacked completely such contacts, the target group was later expanded to include also SMEs with previous contacts, provided that they would be willing to create entirely new contacts and collaborations within the two universities. SMURF covered the cost for the researcher during an initial period of collaboration and thus created the possibility for long-lasting interactions. Every new collaboration was financed with up to $€ 33.000$ via the regional EU funds.

SMURF covered four scientific domains reflecting the need of academic knowledge of regional businesses: life science, material sciences, environmental technology (Green Tech/Clean Tech), and humanities and social sciences. The PISOs searched for SMEs interested in collaborations with academia via various channels, from personal contacts to general information forums, and even AIMday.

In the first phase, the selected companies were contacted, and if they were willing to participate in SMURF, the PISOs discussed with them their needs and searched for researchers suitable for addressing those needs. This was followed by a second phase in which actual collaborative projects were carried out. A project plan was drafted by the company and the researcher together with the PISO. This project plan was then used by the company as an application for financial support from the SMURF committee, and agreements were signed by both the company and the researchers if the application was granted. The collaborations were thereafter started and financing given to the researcher's department after verifying that the project plan was followed.

In the third and final phase, after the conclusion of the collaboration project, SMEs and researchers were invited to meet and discuss new collaborations, sponsored by UUI or third party funders, possibly also with other researchers. Next to the short-term result of starting a specific collaboration, SMURF also aimed to involve researchers and 
companies in long-term relationships, whereby more joint funding could be sought or concrete effects such as joint publications or patents obtained. Another goal with the project was to contribute to regional growth by creating new employments in the participating companies.

\section{Effects of Uppsala University's Interaction-Stimulating Tools}

Many of the effects of the above tools are difficult to measure since they may develop under a long time frame and be embedded in other activities, inside the target organization or in other collaboration settings (Pavitt 2004; Håkansson and Waluszewski 2007). The effects that are directly measurable are the opinions of the participants and the concrete projects and collaboration which can be directly linked to the specific tool. Our review of these effects starts with trust and participation in UUI's activities ("Trust and Number of Participants in UUI's Activities"), followed by the effects of AIMday ("AIMday's Effects") and the actual collaborations resulting from AIMday and the SMURF tool ("Collaborations Started Between Academic Researchers and Companies").

\section{Trust and Number of Participants in UUI's Activities}

Activities like targeted meetings (AIMday and other) have gained more and more attention both from faculty and from business representatives. A general survey in 2013 among all researchers and $\mathrm{PhD}$ students at Uppsala University showed that the share of respondents who had a personal experience from working with these organizations had increased four times since the previous survey in 2010, from 7 to $28 \%$. Furthermore, those who had a personal experience of working with these organizations also expressed a great confidence in the abilities of the PISOs, finding the meetings both efficient and valuable, and $95 \%$ of them would recommend their colleagues to contact them if needed (Mattsson 2011, 2013). Despite the notable difficulties in measuring trust, this "willingness to recommend" is a proxy indicating the high trust of researchers in UUI's PISOs.

The number of participants in UUI's activities can be used as another indicator of trust, as participation is a first step towards cooperation and concrete collaborations (Baraldi et al. 2013). Over 1300 researchers and about 1000 representatives from companies and external organizations are involved yearly. This includes nearly 400 companies per year, about half of which are SMEs (see Fig. 5).

\section{AIMday's Effects}

The immediate effect of AIMday are the specific interactions between the participating academicians and representatives from companies and external public organizations, such as municipalities and schools: While participating enables these actors to learn to know each other and create new contacts, the specific discussions of practitioners' questions entail exchange of knowledge and joint activities which are at the basis of cooperation. According to semi-structured interviews conducted in 2011 (eight with industry representatives and five with researchers), AIMday provides several values 


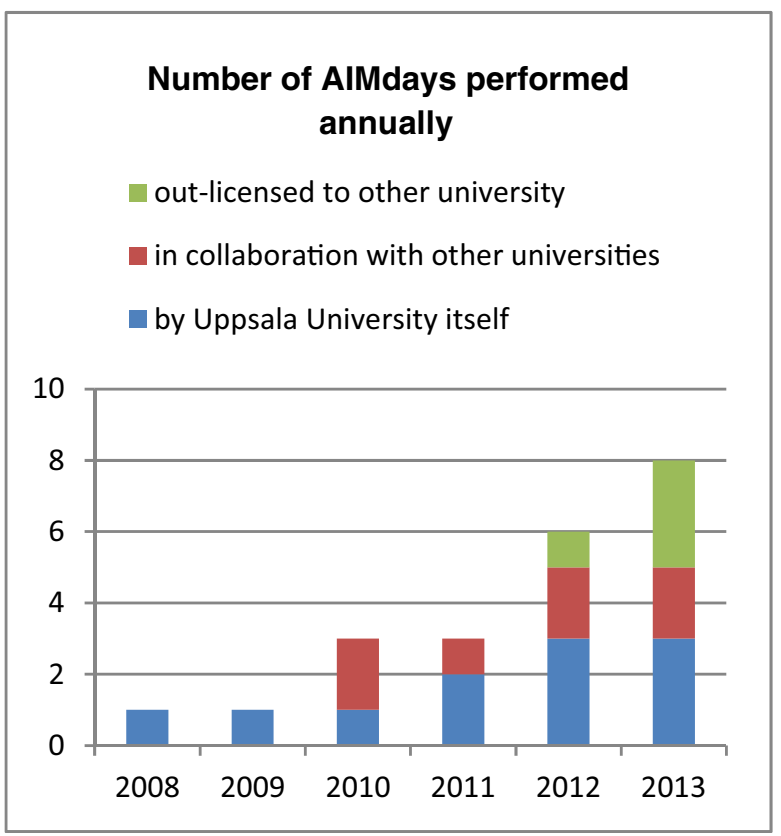

Fig. 5 Number of companies and external organizations participating in UUI's activities

both to companies and researchers; companies see AIMday as a good opportunity to screen the competences and expertise available at the university and create new networks (Baraldi et al. 2011a, b). Spin-off companies use AIMday to meet researchers from other areas of expertise than the university department that span them off. Large companies can find $\mathrm{PhD}$ students for future employment but can also receive access to special analysis equipment (Ibid.). The foremost reason for researchers to attend AIMday is the opportunity to identify different research projects, possible funding, to find new and maintain old contacts, to increase self-esteem and also to broaden knowledge and keep their academic research in contact with the "real world".

Participants' opinions on these interactions were also collected in 2013 via a large survey sent to 1118 persons, 706 researchers and 412 practitioners, which yielded a response rather of respectively 21 and $36 \%$. Table 1 shows that the greatest majority of participants, both from academia and industry, believe that AIMday facilitates interactions between these two groups and creations of new contacts, while enabling science to become more useful to practitioners. For $51 \%$ of practitioners, AIMday has provided practically useful knowledge for their jobs, and for $26 \%$ of them, such knowledge has even helped solving concrete problems. As for academicians, two thirds of them believe that AIMday helps them to better understand the challenges faced by practitioners. However, $48 \%$ of researchers have little use of AIMday discussions in their research, and as many as $69 \%$ could not use them to solve their research problems. This finding is not surprising as AIMday is a tool totally focused upon discussing the issues of companies: Nonetheless, $11 \%$ of academicians could solve specific problems in their work thanks to participation in an AIMday. 


\section{Collaborations Started Between Academic Researchers and Companies}

So far, we have reviewed the effects covering all typologies of university-industry interactions and especially the weaker interaction forms of participation, contacts and cooperation (Baraldi et al. 2013). Moving to stronger interaction forms, it is now relevant to probe into the extent of actual collaborations that can be traced back to the AIMday and SMURF tools. As for AIMday, Table 1 shows that the majority of both academic researchers and industrial representatives think that this tool, in general, facilitates the creation of useful collaborations. And, even if the mention of personal involvement in such collaborations drops considerably, still $22 \%$ of the researchers and as much as $40 \%$ of the industrial representatives claim that their participation on AIMday has led to a collaboration project. However, even if on-going follow studies have identified over a dozen such projects, it is very hard to specify the actual number of collaborations attributable to AIMday, as there is no requirement for participants to report collaborations and they may emerge in a rather unplanned way more than 1 year after the event.

As for SMURF, all the 28 SMEs involved have been interviewed and they expressed that they have gained "soft" values ranging from increased knowledge to improvement or development of products, services and methods, which they regard as very valuable for them. Moreover, a majority of these SMEs want to extend or deepen the existing collaboration with a certain researcher or find new collaborations.

Table 2 shows that UUI's PISOs contacted in the first stage 355 companies and informed them about the possibility to use this tool to gain relevant knowledge from the university. Out of these 355 initial contacts, 28 companies (about $8 \%$ ) got involved in a first collaboration project. Four of the companies got involved in two projects, resulting in a total of actual 32 collaborations. The seemingly weak conversion rate of $8 \%$ also depends on the fact that the target group were companies with no previous experience of interactions with universities. Among the 28 companies who participated in SMURF, 24 also did participate in the follow-up networking activities and showed an active interest in establishing long-lasting interactions with the universities. Followup interviews with the companies clearly show that the SMEs' willingness to stay in contact with and use academic resources is an effect of the SMURF tool.

Despite the academically "inexperienced" industrial partners, the new and exploratory nature of collaborations, conducted with limited resources, SMURF produced six

Table 2 The effects of the SMURF project

Number of SMEs met for information purposes

355

Number of fruitful meetings between SMEs and academic researchers

51

Number of collaboration projects initiated

32

Number of projects having as goal to:

$\begin{array}{ll}\text { - gain new knowledge: } & 24 \text { realized } \\ \text { - develop new product/service: } & 3 \text { realized } \\ \text { - improve a method/product: } & 11 \text { realized } \\ \begin{array}{c}\text { Number of employments created in the } \\ \text { participating SMEs }\end{array} & 7\end{array}$

- gain new knowledge:

24 realized

realized

7 
academic publications. Moreover, this tool enabled seven SMEs to hire new employees, despite the short time frame of each collaboration, the small size of the companies, the limited financial resources granted and the lack of previous contacts. To summarize, SMURF allowed the participating companies to validate products and to gain new knowledge which they find valuable for further development. As one of the company representatives declared, "This has resulted in an additional stone in building our house", stressing that the results have been valuable but it might take a long time before the effects will be visible.

\section{Discussion}

We discuss first the functioning of interaction-stimulating tools introduced by UUI and their effects, relying on the theoretical framework of "Theoretical Framework" section; then, we identify six challenges associated with these tools and with targeting open innovation in general ("Challenges in Targeting Open Innovation Interactions" section).

The effects of UUI's tools range from the participation of industry and public agency representatives in their activities to changed attitudes among academicians and practitioners and from simple contacts to deeper industry-academia collaboration projects. Some of these tools (see SMURF) also had as effects employments that can contribute to regional growth. Therefore, UUI operates within a triple helix (Etzkowitz and Leydesdorff 2000). Moreover, since this organization also regularly stimulates collaboration projects involving the humanities and broader parts of the civil society as partners, UUI is embracing a quadruple helix model (Carayannis and Campbell 2010).

The depth, in terms of influence on the involved parties, and persistence over time of the above effects can vary greatly. For instance, while contacts gained at AIMday may persist over the long term even without having any deep influence on the interacting parties, a collaboration project such as those created by SMURF may last for just a month but have tangible effects such as new products being developed. Despite the variety of these effects, there seems to be a logic in the operations of UUI based on starting from many, broad and diffuse interactions and then targeting these by focussing on specific counterparts and projects. While open innovation interactions and other academic engagement activities (Perkmann et al. 2013) risk remaining too broad and shallow to generate concrete and long-lasting effects, the tools described in this paper provide the opportunity for the university management of acting in a targeted way.

For instance, UUI's PISOs act as "knowledge brokers" (Meyer 2010), capable of exploiting their industrial and academic contact nets in order to find which specific partners from academia and industry can really be matched. But prior to this concrete matching, PISOs have the ability (1) to understand each specific actor's needs and goals, namely the academic incentives and industrial needs, and then (2) to build trust among the two parties, as witnessed by the fact that as many as $95 \%$ of researchers would recommend relying on the PISOs to their colleagues. Building trust is, in turn, fundamental to progress from open but shallow interactions to deeper ones, based on a more concrete matching, mutual commitment of resources and possibly a long-term relationship between two specific parties (Håkansson and Snehota, I 1995; Baraldi et al. 2013). Figure 6 analyses how PISOs and the other two tools, AIMday and SMURF, intervene in the basic mechanisms underlying university-industry interactions 
(identified from the IMP approach reviewed in our theoretical review) and in different typologies of such interactions (see Baraldi et al. 2013). The mechanisms underlying these interactions, presented in the matrix rows, are building trust, overcoming language barriers, resource commitment and recognition of both academic incentives and industrial needs; whereas, the horizontal axis presents interactions of increasing depth when moving from left to right in Fig. 6.

UUI's PISOs operate in the intersection industry-academia and can potentially support all types of interaction and underlying mechanism on Fig. 6. However, more specifically, they intervene to create mutual trust and act as mediators so that all parties can benefit from interaction. PISOs are also negotiators who can facilitate decisions by both researchers and industry to commit resources within specific cooperation and collaborations, ideally all the way to long-term relationships. However, in order to exploit these interaction mechanisms, PISOs need to embody the double competences and experiences of both industry and academia, which are necessary to understand the incentives and needs of both counterparts and also help overcome the language barriers between them (Wright et al. 2008). Moreover, PISOs with double competence may help overcome the problem identified by Hertzfeld et al. (2006) that US companies often try to bypass TTOs because they perceive TTO staff lack business knowledge and are obsessed with generating IP incomes to universities.

Moving to AIMday, the role of this tool in the grid of Fig. 6 is somehow more restricted than that of PISOs: AIMday supports trust building when researchers and industry concretely cooperate during AIMday discussions. The whole preparation process of AIMday, with selection and reformulation of questions, also helps overcome language barriers, from first contacts to the cooperation happening at the venue. AIMday also implies a commitment of resources (knowledge and time primarily), although limited to the cooperation achieved during the very discussions and only seldom stretching to actual collaborations. Finally, AIMday is particularly apt to incorporate the academic incentives (search for funds or self-esteem) and the industrial needs (e.g. practitioner-led discussion questions, browsing for competence and gaining new insights or solving specific technical problems).

Finally, SMURF is the interaction-stimulating tool with the most restricted focus in the grid of Fig. 6: First of all, it operates mostly at the level of concrete collaboration

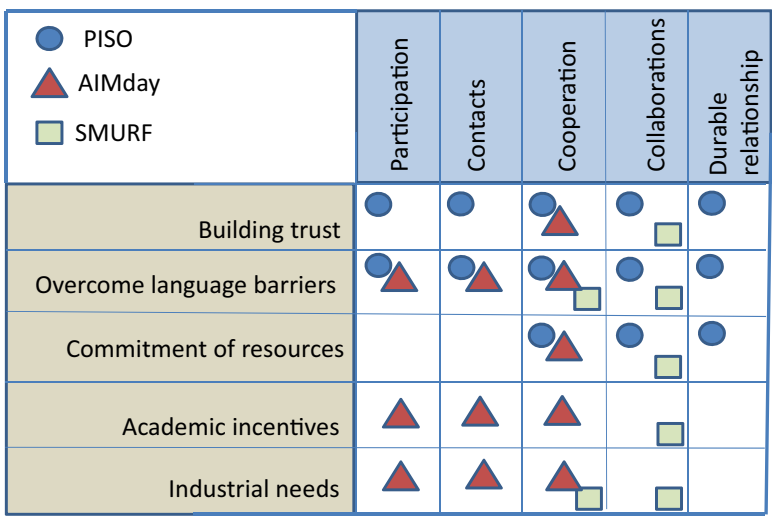

Fig. 6 Connecting interaction-supporting tools to interaction mechanisms and interaction typologies 
projects, covering however all of its underlying mechanisms, from provision of resources (finance by UUI, knowledge by researchers and time by firms) to academic incentives (additional funds) and industrial needs (solution to specific technical problems). SMURF also embraces partly the cooperation level because a collaboration project is selected only after academia and industry representatives have exchanged ideas and knowledge to formulate a common project plan-thereby overcoming language barriers - even if the goals of such a plan reflect mostly industrial needs, whereas the incentives for academia, such as funding and possible publications (six of them emerged from SMURF), appear in the subsequent collaboration project.

The SMURF and AIMday tools accordingly stimulate university-industry interactions characterized by different depth and durability. AIMday seems best suitable for participations, contacts and shallower cooperation, whereas SMURF, even if it starts from participation and cooperation, definitely focuses on deeper collaborations (see Fig. 7). Despite some overlap in their effects, a broad arsenal of more or less specialized tools helps better target the various types of interactions. Some effects do build on others: For instance, it is unlikely that a deep and durable relationship immediately appears "alone" without prior interactions (Håkansson and Snehota, I 1995). According to our theoretical framework (see Fig. 1), one can trace the following ladder of interactions: participation-contacts-cooperation-collaboration relationship (Baraldi et al. 2013).

In particular, as the example of SMURF indicates, without previous relationships with companies (SMEs in this case), it takes a large number of external participants to obtain a certain number of actual collaborations, and most likely, only very few of the latter will turn into long-term and deep relationships. This progressive (self-)selection of interacting parties before moving to the next and deeper level of interaction corresponds to an "academic engagement funnel" (Jonsson et al. 2014a, 2014b). Considering the cultural barriers between industry and academia (Plewa et al. 2005) and the importance of trust for building long-term and deep relationships (Plewa and Quester 2007; Håkansson and Snehota, I 1995), UUI's PISOs play a key role for propelling industry-academia interactions through this academic engagement funnel.

There are also important connections and dependencies between the various tools and their effects. Even if AIMday and SMURF create specific interactions and allow knowledge exchanges between researchers and practitioners, these tools alone would not enable these effects; rather, it takes a considerable amount of work by the PISOs to gain the trust of researchers and practitioners, and this trust must be established before all parties start believing in the value of cooperation and collaborations. Finally, there is also another mutual effect between the various tools: Next to favouring trust building
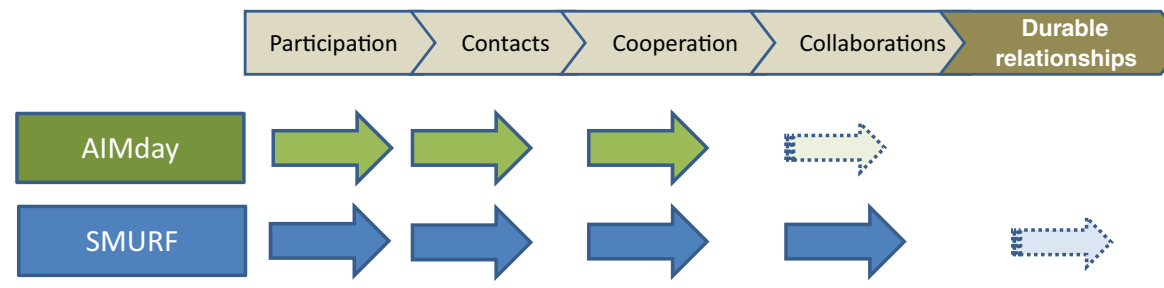

Fig. 7 AIMday and SMURF's effects on the "academic engagement funnel". Modified from: Jonsson et al. (2014a); Baraldi et al. (2013). Direct effect (filled arrows), indirect/long-term effect (dotted arrows) 
and targeted interactions, the AIMday and SMURF tools also expand the contacts of all involved parties (PISOs, researchers and industry/public organizations). Thus, the tools described in this paper provide the PISOs and the participating researchers with more company linkages, while enhancing the reputation of the innovation supporting units in the eyes of industry and other external organizations. A more diffuse effect of these tools and of the PISOs' work is researchers' more positive attitudes towards commercialization and utilization of academic results, also manifested in a fourfold increase of individual researchers meeting PISOs at Uppsala University (Mattsson 2011, 2013).

\section{Challenges in Targeting Open Innovation Interactions}

University and industry might need each other, and a well-managed interaction can result in a fruitful and mutual development for the best of all parties. However, there are also a set of general and specific challenges associated with targeting interactions and using the tools presented in this paper. We identified six such challenges. A first general challenge is that academia is not a normal first choice for firms looking for partners to develop their business (Håkansson 1989), and the need of input from academic research is intermittent, depending on different lifetime cycles of products and market development (Håkansson and Waluszewski 2007). On the other side of the interaction, even if academicians may obtain new relevant knowledge and resources from industry (as shown by the AIMday and SMURF illustration), this is an intermittent process rather than daily interactions, which for most academic researchers are dominated by other events such as conferences, publishing and peer networking. Intermittent or "interimistic" relationships are known to be difficult to manage and prioritize (Lambe et al. 2000). Thus, academia-industry interaction most often does not develop by itself. Our case shows that taking the implementing steps, from research policy and abstract theories about triple helix and mode $2 / 3$ down to concrete activities on the "university floor", is not easy. Many other challenges have to be tackled, and even if the recruitment of double-competent PISOs and the use of interaction-stimulating tools such AIMday and SMURF enables to address some challenges, several other remain or even accompany the use of these tools.

A second major challenge for university management (but also researchers investigating academic engagement) is the lack of clear codified results visible with a relative short time lag. Reflecting the problem of tracing collaborations and innovations coming out from AIMday, many studies have showed that it takes years or decades before a transferred knowledge shows up as an innovation in an existing company, and when it does, it will often be embedded in something else and hard to recognize (Pavitt 2004; Håkansson and Waluszewski 2007; Baraldi and Launberg 2013). This is probably a major reason why both policymakers and innovation researchers emphasize more the traditional commercialization funnel, since it is easier to count its codified results such as the number of disclosures, patents, new ventures and out-licence agreements.

Looking more specifically at the tools employed by Uppsala University, a third challenge is that AIMday needs a lot of preparatory work to be successful and it is not always obvious for the university management or the individual researcher that the cost of this investment will pay off by increased incomes from contract research and external grants for collaborative research. Careful advanced planning of the event is crucial but not easy to achieve in a fast-changing environment. Further, UUI's 
experience with SMURF highlights a fourth challenge: the great difficulties and extra resources involved in trying to let academically unrelated SMEs exploit academic research. SMEs can hardly see a major advantage in being involved, and academicians view the often very practical problem of an SME as adding little value to their research. Therefore, it resulted difficult to find interested companies in the SME "segment". As found in this paper, the academic engagement funnel narrows steeply and you need to invest in time-consuming contacts with a lot of SMEs to finally get one match, a collaboration ( $8 \%$ conversion rate in the case of SMURF). Similarly to the "awarenessinterest-desire-action" (AIDA) model in marketing (Russel 1921; Barry 1987), PISOs first need to make companies aware of their tool, then raise their interest in it and instil a desire to interact via the tool, before they finally take action by a concrete collaboration. Not surprisingly, many companies (or "potential customers") are lost during the AIDA process. In the case of SMURF, the original task to target SMEs with no previous experience from interaction with universities had to be abandoned early on and replaced with experienced SME seeking new university contacts. This challenge may raise the question whether it is worth the efforts from the university to act as a missionary among uninterested SMEs, instead of focussing on the "low hanging fruits" of interactions with already motivated industrial partners. This may however be in conflict with policy goal for regional development.

A fifth challenge is the costs associated with the reviewed interaction supporting tools. Because of the considerable amount of working hours required to operate interaction-stimulating tools like AIMday and SMURF and the relative sparse outcomes in the numbers of collaborative projects and additional external resources, university management may hesitate investing the necessary time and resources. The same goes for the high cost of recruiting skilled and experienced PISOs, whose salary levels need to be considerably higher than the average university administrator's in order to attract them from high-pay positions in industry or other public organizations. While colliding with budget constraints, PISOs' high salaries may also cause internal tensions with other university management personnel and faculty. Avoiding these high recruitment costs by internal recruitment of PISOs may lead to appointing persons who lack the managerial experience from external organizations and who cannot contribute a new external network of connections or may even be seen as bottlenecks by academia and industry rather than facilitators (Hertzfeld et al. 2006; Link et al. 2007; Litan et al. 2007).

As implied also by our theoretical framework (see Fig. 1), the various elements and tools deployed by a university to stimulate interactions with industry act as an integrated whole, whereby their effects can also sustain each other. Accordingly, some tools are likely to display some dependence on the others in order to be operated and produce effects. In particular, both AIMday and SMURF are tools which UUI's PISOs have both contributed to develop and implemented and which they currently operate. Therefore, a sixth challenge lies in using the various interaction-stimulating tools in concert: For instance, even if this study did not explicitly address this issue, one may question the functioning of AIMday and SMURF if they were operated by officers without the same qualifications, experience and double competence as UUI's PISOs. The system is a sensitive one, and it is possible that changing some element (e.g. using PISOs with only business experience as Uppsala University did initially) will make the other interaction-supporting tools much less useful: For instance, PISOs unable to be 
accepted by both parties - researchers and companies alike-would have troubles in creating the trust among the parties on which the more operative tools rely in order to produce specific interactions (see Fig. 1).

\section{Summary and Conclusion}

The aim of this paper was to investigate the role of university management in academic engagement and, more specifically, to investigate how university management can "target" open innovation interactions and stimulate with professional support the emergence of specific university-industry relations. These issues have been investigated in a case study about Uppsala University's innovation supporting organization which addresses three key questions: (1) Which mechanisms and tools do the university management apply in order to create targeted open innovation interactions? (2) Which effects, in terms of specific university-industry interactions, emerge? (3) Which challenges are associated with these processes and tools?

As for the first two questions, we found that staff with double competence and experience of both academia and industry is important for managing academia-industry interactive processes as these PISOs support trust building, resource mobilization and overcoming language barriers, thereby enabling open innovation interactions to evolve towards focused collaborations and possibly long-term relationships. Achieving such effects requires however also devising specific interaction-stimulating tools, such as AIMday and SMURF, which create different effects in terms of interaction depth: respectively, participation by industry and academia via effective meetings enabling immediate cooperation and more substantial collaborative projects. Operated by PISOs with double competence, tools such as those reviewed in this paper offer more targeted interaction solutions which concretize within specific and deeper interactions the promises of the open innovation paradigm.

However, addressing our third research question above, we also identify the following six challenges in targeting open innovation interactions: (1) the intermittent nature of university-industry interactions makes them hard to prioritize; (2) lack of codified ways to trace effects which are typically long term, complex and indirect; (3) extensive and time-consuming preparatory work in deploying tools such as AIMday; (4) the extra resources and low conversion rates in engaging academically unrelated SMEs orient university management to focus on the low hanging fruits of companies with established academic interactions; (5) high costs of recruiting PISOs with double competence and of running tools such as AIMday and SMURF; and (6) the interdependencies between the various tools make the system sensitive to changes in one component.

Thus, a modest conversion rate and high costs for running the above tools to create deeper academia-industry collaborations constitute a major challenge. On the other hand, if diversified interactions with industry and the surrounding society are a prioritized strategy for the university, the increased overhead represented by doublecompetent PISOs and the "extra work" needed to arrange an AIMday or run a SMURF-like program may be well-spent resources. This issue could ideally be settled by means of a cost-benefit analysis, which is however beyond the scope of this paper (for a provisional analysis of this type, see Jonsson et al. 2014a). This further research 
should ideally take a longer time frame than this study, long enough to verify if the investments pay off in terms of all collaborations associated with the selected tools (and their values for the involved parties), increased research funding and university reputation.

Still, leaving aside these formalized evaluations, our results indicate that the tools used at Uppsala University are not only beneficial for making the so called mode 2 activities more effective but also help the university to follow a mode 3 of knowledge creation, whereby university, government, industry and civil society interact in a quadruple helix characterized by a pluralism of knowledge creation and innovation approaches. Uppsala University's thus seems to operate simultaneously according to a mode 1 and a mode 2 of knowledge creation and application (Gibbons et al. 1994), combining and switching between both modes in a way that correspond to a mode 3 of knowledge production (Carayannis and Campbell 2010). The reviewed interactionstimulating tools also increase the trust of researchers in the innovation supporting organization and improve their attitudes towards commercializing science, while expanding the network of contacts for all involved parties. An interesting hypothesis is therefore that trust and contacts can induce individual researchers to commercialize their scientific results via the linear funnel also. Further studies could accordingly investigate whether the linear commercialization funnel (Clarysse et al. 2005) and the interactive academic engagement approach are really two separate and mutually exclusive innovation tracks or can instead support each other (cf. Jonsson et al. 2014b).

Our study addressed the research gap regarding organizational support in the guise of industrial liaison offices or business relationship offices pointed out by Perkmann et al. (2013) by indicating which tools can be used to target and focus industryacademia interactions, their effects and associated challenges. However, much research still needs to be done on this topic. Many results of this type of organizational support are hard to trace, as they are indirect, manifested at unexpected places and require time to emerge (Pavitt 2004; Håkansson and Waluszewski 2007). Considering our specific case, a lot of the effects of the reviewed tools still need to be codified, and more research is needed to understand their impact over time. We recommend that the applied indicators used can capture the broad range of values created for several stakeholders: for instance, individual researchers, research leaders, heads of departments, university management, SMEs and large companies, final users and, not least, students. Also, the time frame for tracing results and effects will need to be expanded from the current 1 to 5 years in order to embrace the complex and long-term dynamics of innovation, which typically extend over decades.

Open Access This article is distributed under the terms of the Creative Commons Attribution 4.0 International License (http://creativecommons.org/licenses/by/4.0/), which permits unrestricted use, distribution, and reproduction in any medium, provided you give appropriate credit to the original author(s) and the source, provide a link to the Creative Commons license, and indicate if changes were made.

\section{References}

Agrawal, A., \& Henderson, R. (2002). Putting patents in context: exploring knowledge transfer from MIT. Management Science, 48(1), 44-60. 
Anderson, J. C., \& Narus, J. A. (1990). A model of distributor firm and manufacturer firm working partnerships. Journal of Marketing, 54, 42-58.

Ankrah, S. N., Burges, T. F., Grimshaw, P. \& Shaw, N. E. (2013). Asking both university and industry actors about their engagement in knowledge transfer: what single-group studies of motives omit. Technovation, $33,50-65$.

AUTM (2012). U.S. licensing activity survey, FY2011.

Balconi, M., Brusoni, S., \& Orsenigo, L. (2010). In defence of the linear model: an essay. Research Policy, 39, $1-13$.

Baraldi, E., \& Launberg, A. (2013). The commercialization of science as an embedding process: the case of PET radiotracers at Uppsala University. Atlanta: Paper presented at the 29th IMP Conference.

Baraldi, E., Lindhal, M., \& Severinsson, K. (2011a). Entrepreneurial universities seeking new ways to commercialize science: the case of Uppsala University's AIMDay ${ }^{\mathrm{TM}}$. Stockholm: Paper presented at the Nordic Academy of Management 22-24 August.

Baraldi, E., Gregori, G. L., \& Perna, A. (2011b). Network evolution and the embedding of complex technical solutions: the case of the Leaf House network. Industrial Marketing Management, 40(6), 838-852.

Baraldi, E., Forsberg, P., \& Severinsson, K. (2013). Crafting University-Industry Interactions: a typology and empirical illustrations from Uppsala University, Sweden. Amsterdam: Proceedings of the 2nd UniversityIndustry Interaction Conference.

Baraldi, E., Ingemansson, M., \& Launberg, A. (2014). Controlling the commercialization of science across organizational borders. Four cases from two major Swedish universities, Industrial Marketing Management, 43(3), 382-391.

Barry, T. E. (1987). The development of the hierarchy of effects: an historical perspective. Current Issues \& Research in Advertising, 10(2), 251-295.

Bercovitz, J., \& Feldmann, M. (2006). Entrepreneurial universities and technology transfer: a conceptual framework for understanding knowledge-based economic development. Journal of Technology Transfer, $31,175-188$.

Carayannis, E. G., \& Campbell, D. (2006). Knowledge creation, diffusion and use in innovation networks and knowledge clusters. New York: Praeger Publishers.

Carayannis, E. G., \& Campbell, D. (2009). 'Mode 3' and 'Quadruple Helix': toward a 21st century fractal innovation ecosystem. International Journal of Technology Management, 46(3/4).

Carayannis, E. G., \& Campbell, D. (2010). Triple helix, quadruple helix and quintuple helix and how do knowledge, innovation and the environment relate to each other? A proposed framework for a transdisciplinary analysis of sustainable development and social ecology. International Journal of Social Ecology and, Sustainable Development, 1(1), 41-69.

Carayannis, E. G., \& Rakhmatullin, R. (2014). The quadruple/quituple innovation helixes and smart specialisation strategies for sustainable and inclusive growth in europe and beyond. Journal of Knowledge Economy, 5, 212-239.

Chesbrough, H. W. (2003). Open Innovation: the new imperative for creating and profiting from technology. Boston: Harvard Business School Press (March).

Clark, B. R. (2003). Sustaining change in universities: continuities in case studies and concepts. Tertiary Education and Management, 9, 99-116.

Clarysse, B., Wright, M., Lockett, A., Van de Velde, E., \& Vohora, A. (2005). Spinning out new ventures: a typology of incubation strategies from European research institutions. Journal of Business Venturing, 20, 183-216.

Cohen, W. M., Florida, R., Randazzese, L., \& Walsh, J. (1998). Industry and the academy: uneasy partners in the cause of technology advance. In R. G. Noll (Ed.), Challenges to Research Universities (pp. 171-199). Washington DC: Brookings Institution Press.

Dahlander, L., \& Gann, D. M. (2010). How open is innovation. Research Policy, 39, 699-709.

Debackere, K., \& Veugelers, R. (2005). The role of technology transfer organizations in improving industry science links. Research Policy, 34, 321-342.

Eklund, M. (2007). Adoption of the Innovation System Concept in Sweden, doctoral thesis, The Department of Economic History, Uppsala University.

Etzkowitz, H. (2001). The Second academic revolution and the rise of entrepreneurial science. IEEE Technology and Society Magazine, (Summer), 18-29.

Etzkowitz, H., \& Leydesdorff, L. (2000). The dynamics of innovation: from National Systems and "Mode 2" to a Triple Helix of university-industry-government relations. Research Policy, 29, 109-123.

Etzkowitz, H., Webster, A., Gebhardt, C., \& Terra, B. R. C. (2000). The future of the university and the universityofthefuture: evolution of ivory tower to entrepreneurial paradigm. Research Policy, 29, 313330. 
Fishburn, C. S. (2014). Easy Access IP: ahead of the game or easy way out? SciBX7(11), doi:10.1038/scibx. 2014.303

Gertner, D., Roberts, J., \& Charles, D. (2011). University-industry collaboration: a CoPs approach to KTPs. Journal of Knowledge Management, 15(4), 625-647.

Gibbons, M., Limoges, C., Nowotny, H., Schwartzman, S., Scott, P., \& Trow, M. (1994). The new production of knowledge: the dynamics of science and research. In Contemporary Societies. London: Sage.

Håkansson, H. (Ed.). (1982). International Marketing and Purchasing of Industrial Goods: Interactive Approach. Chichester: Wiley.

Håkansson, H. (1989). Corporate Technological Behaviour, Cooperation and Networks. London: Routledge.

Håkansson, H., \& Snehota, I. (1989). No business is an island: the network concept of business strategy. Scandinavian Journal of Management, 5(3), 187-200.

Håkansson, H., \&Snehota, I. (Eds.)(1995). Developing Relationships in Business Networks. London: Routledge.

Håkansson, H., \& Waluszewski, A. (Eds.). (2007). Knowledge and Innovation in Business and Industry. The importance of using others. London: Routledge.

Håkansson, H., Ford, D., Gadde, L.-E., Snehota, I., \& Waluszewski, A. (2009). Business in Networks. Chichester: Wiley.

Hertzfeld, H. R., Link, A. N., \& Vonortas, N. S. (2006). Intellectual property protection mechanisms in research partnerships. Research Policy, 35, 825-838.

Jacobsson, S., \& Perez Vico, E. (2010). Towards a systemic framework for capturing and explaining the effects of academic R\&D. Technology Analysis \& Strategic Management, 22(7), 765-787.

Jones-Evans, D., Klofsten, M., Andersson, E., \& Pandya, D. (1999). Creating a bridge between university and industry in small European countries: the role of the Industrial Liaison Office. $R \& D$ Management, 29, 4756.

Jonsson, L., Baraldi, E., Larsson, L.-E., Forsberg, P., \& Severinsson, K. (2014a). Building professional university structures to support knowledge exchange for mutual benefits. Barcelona: Proceedings of the 3d University-Industry Interaction Conference.

Jonsson, L., Baraldi, E., \& Larsson, L.-E. (2014b). A broadened innovation support for mutual benefits. Setif: Paper presented at the 4 thCOSINUS Conference.

Lai, W.-H. (2011). Willingness to engage in technology transfer in industry-university collaborations. Journal of Business Research, 64, 1218-1223.

Lambe, C. J., Spekman, R. E., \& Hunt, S. D. (2000). Interimistic relational exchange: Conceptualization and propositional development. Journal of the Academy of Marketing Science, 28(2), 212-226.

Levin, M., \& Greenwood, D. (2001). Pragmatic action research and the struggle to transform universities into learning communities. In P. Reason \& H. Bradbury (Eds.), Handbook of Action Research: Participative inquiry and practice (pp. 103-113). London: Sage.

Lincoln, Y., \& Guba, E. (1985). Naturalistic Inquiry. Thousands Oaks: Sage Publications.

Link, A. N., Siegel, D. S., \& Bozeman, B. (2007). An empirical analysis of the propensity of academics to engage in informal university technology transfer. Industrial and Corporate Change, 16(4), 641-655.

Litan, R. E., Mitchell, L., \& Reedy, E. J. (2007). The university as innovator: bumps in the road. Issues in Science and Technology, Summer, 2007, 11.

Lundvall, B.-A. (Ed.). (1992). National Systems of Innovation. Towards a Theory of Innovation and Interactive Learning. London: Pinter Publishers.

Mattsson, H. (2011). Hur ser Uppsala universitets forskare på nyttiggörande av forskningsresultat? Report in Swedish available at UU Innovation, Uppsala University. SwecoEurofutures.

Mattsson, H. (2013). Samverkan och nyttiggörande av forskning. Report in Swedish available at UU Innovation, Uppsala University. SwecoEurofutures.

Meyer, M. (2010). The rise of the knowledge broker. Science Communication, 32(1), 118-127.

Morgan, R. M., \& Hunt, S. D. (1994). The commitment-trust theory of relationship marketing. Journal of Marketing, 58(3), 20-38.

Narin, F., Hamilton, K. S., \& Olivastro, D. (1997). Increasing linkage between U.S. technology and public science. Research Policy, 26, 317-330. doi:10.1016/S0048-7333(97)00013-9.

Nilsson, A. S., Rickne, A., \& Bengtsson, L. (2010). Transfer of academic research: uncovering the grey zone. Journal of Technology Transfer, 35(6), 617-636.

Nowotny, H., Scott, P., \& Gibbons, M. (2003). 'Mode 2' revisited: the new production of knowledge. Minerva, 41, 179-194.

Pavitt, K. (2004). Changing patterns of usefulness of university research. opportunities and dangers. In K. Grandin, N. Wormbs, \& S. Widmalm (Eds.), The Science-Industry Nexus. History, Policy, Implications (pp. 119-131). Sagamore Beach: Science History Publications. 
Peças, P., \& Henriques, E. (2006). Best practices of collaboration between university and industrial SMEs. Benchmarking: An, International Journal, 13(1/2), 54-67.

Perkmann, M., Tartari, V., McKelvey, M., Autio, E., Broström, A., D’Este, P., Fini, R., Geuna, A., Grimaldi, R., Hughes, A., Krabel, S., Kitson, M., Llerena, P., Lissoni, F., Salter, A., \& Sobrero, M. (2013). Academic engagement and commercialisation: a review of the literature on university-industry relations. Research Policy, 42, 423-442.

Philbin, S. P. (2010). Developing and managing university-industry research collaborations through a process methodology/industrial sector approach. Journal of Research Administration, 41(3), 51-68.

Plewa, C., \& Quester, P. (2007). Key drivers of university-industry relationships: the role of organisational compatibility and personal experience. Journal of Services Marketing, 21(5), 370-382.

Plewa, C., Quester, P., \& Baaken, T. (2005). Relationship marketing and university-industry linkages: a conceptual framework. Marketing Theory, 5(4), 433-456.

Powell, W. W., Owen-Smith, J., \& Colyvas, J. A. (2007). Innovation and emulation: lessons from American universities in selling private rights to public knowledge. Minerva, 45, 121-142.

Resende, D. N., Gibson, D., \& Jerrett, J. (2013). BTP_-best transfer practices. A tool for qualitative analysis of tech-transfer offices: A cross cultural analysis. Technovation, 33, 2-12.

Rhodes, G., \& Sporn, B. (2002). New models of management and shifting modes and cost of production: Europe and the United States. Tertiary Education and Management, 8, 3-28.

Russel, C. P. (1921). How to write a sales-making letter. Printers' Ink(June 2).

Salter, A. J., \& Martin, B. R. (2001). The economic benefits of publicly funded basic research: a critical review. Research Policy, 30(3), 509-532.

Tether, B. S., \& Tajar, A. (2008). Beyond industry-university links: sourcing knowledge for innovation from consultants. private research organisations and the public science-base, Research Policy, 37, 1079-1095.

Tidd, J., Bessant, J., \& Pavitt, K. (2001). Managing Innovation, Integrating Technological, Market and Organizational Change (2nd ed.). Chichester: Wiley.

Trune, D. R., \& Goslin, L. N. (1998). University technology transfer programs: a profit/loss analysis. Technology Forecasting and Social Change, 57, 197-204.

vonHippel, E. (2005). Democratizing Innovation. Cambridge: The MIT Press.

West, J., \& Gallagher, S. (2006). Challenges of open innovation: the paradox of firm investment in opensource software. $R$ and D Management, 36(3), 319.

Wright, M., Clarysse, B., Lockett, A., \& Knockaert, M. (2008). Mid-range universities' linkages with industry: knowledge types and the role of intermediaries. Research Policy, 37, 1205-1223.

Yin, R. K. (1994). Case study research: Design and methods (2nd ed.). Thousand Oaks: Sage Publications.

Yusuf, S. (2008). Intermediating knowledge exchange between universities and businesses. Research Policy, 37, 1167-1174.

Endnote: AIMday is a trademark registered by Uppsala University, Sweden. 